\title{
PREDIKSI HARGA JAGUNG MENGGUNAKAN METODE FUZZY TIME SERIES dengan atau TANPA MENGGUNAKAN MARKOV CHAIN
}

\author{
Comparison Fuzzy Time Series with and Without Markov Chain: to Forecast of \\ Maize \\ Danung Nur Adli ${ }^{1)}$ \\ 1) Fakultas Peternakan, Universitas Brawijaya Jalan Veteran, Ketawanggede, Kec. Lowokwaru, Kota Malang, \\ Jawa Timur, Indonesia 65145 \\ Email: danungnuradli1994@gmail.com \\ Diterima Pasca Revisi: 25 Februari 2021 \\ Layak Diterbitkan: 1 Maret 2021
}

\begin{abstract}
ABSTRAK
Penelitian ini dilakukan dengan tujuan memprediksi harga pakan jagung menggunakan salah satu model matematika yang disebut fuzzy time series. Data yang didapatkan yaitu data historis atau rentan waktu dari berbagai literasi seperti hargaweb.id, jagungbisi.com, dan BPS dari tahun 2020-2021, kuarter pertama. Data tersebut nantinya akan dijadikan bahan perhitungan. Data dianalisa menggunakan $R$ Studio. Kemudian algoritma fuzzy time series. hasil penelitian fuzzy time series menghasilkan prediksi harga pada jagung menggunakan time series. Memprediksi harga akan cenderung berubah dari kisaran Rp/ 4.000-4.400,- yang mana tingkat error hanya ada di level 8,23.Logika fuzzy atau time series mampu menyajikan prediksi harga jagung pada tahun 2020-2021 dengan keakuratan dengan tingkat error $8.23 \%$ artinya tidak berbeda jauh. Kedepannya banyak model matematika yang bisa digunakan untuk memprediksi dari harga bahan baku atau aspek lainnya pada industri peternakan.
\end{abstract}

Kata Kunci: Fuzzy time series, harga, jagung, markov chain, model matematika

How to Cite:

Adli, D. N. (2021). Prediksi Harga Jagung Menggunakan Metode Fuzzy Time Series Dengan Atau Tanpa Menggunakan Markov Chain. Jurnal Nutrisi Ternak Tropis 4 (1) 49-54
*Corresponding author:

Danung Nur Adli

Email: danungnuradli1994@gmail.com

Fakultas Peternakan, Universitas Brawijaya Jalan Veteran, Ketawanggede, Kec. Lowokwaru, Kota Malang, Jawa Timur, Indonesia 65145 


\section{ABSTRACT}

The aim of this research were to determining and predicted price of maize using fuzzy time series using without or without markov chain. The scope using in this study were price of maize taken from BPS and other related websites to use. The steps were divided into 4 steps there were: determine the set of universes, create fuzzy sets, perform fuzzification, create FLR, create FLRG and defuzzify using $R$ Studio. The result showed that Fuzzy Time Series with and without Markov Chain method performs better in the forecasting ability in short-term period prediction and the values of Mean Absolute Percentage Error (MAPE) and Mean Square Error (MSE) tends to be smaller than the Fuzzy Time Series without Markov Chain. It can be concluded the number of exported can be used Fuzzy time series.

Keywords: Estimates, fuzzy time series, markov chain, mean absolute percentage error.

\section{PENDAHULUAN}

Pada tahun 2019, WHO mengumumkan (2019n-cov) sebagai pandemik yang menjadikan wabah ini adalah sebuah pandemik global. Wabah pandemik ini menyebar ke seluruh negara tidak terkecuali negara Indonesia. Atas dasar pertimbangan ini Indonesia melakukan langkah preventif pada semua bidang tidak terkecuali bidang peternakan. Melalui PERMENDAG 10/2020 tidak diperbolehkan produk hewan hidup atau pakan masuk atau transit ke Indonesia. Hal ini menyebabkan dampak sektor peternakan di Indonesia.

Salah satu yang mempengaruhinya adalah produk utama pakan ternak yaitu Jagung. Dikutip dari Kementerian Pertanian (Kementan) menyebut, sejak JanuariSeptember 2020, impor jagung sudah mencapai 911.194 ton dengan nilai US\$ 233,47 juta. Bila dibandingkan pada periode yang sama tahun lalu, impor jagung sudah mencapai 1,07 juta ton. Hal itu juga menyebabkan meningkat-nya harga jagung di peternak menjadi dikisaran Rp. 3.8004.400,-. Hal ini, dipengaruhi oleh beberapa faktor seperti cuaca, harga bibit jagung, ketersediaan benih di pasaran. Hal ini diperburuk dengan adanya wabah COVID19 sepanjang tahun 2019 akhir hingga 2021 awal. Kenaikan harga bahan pakan berdampak pada kenaikan harga pakan pada tingkat peternak. Hal ini menimbulkan permasalahan baru bagi pelaku dari hulu ke hilir (Sjofjan et al., 2019, 2020). Sementara, Pertambahan jumlah penduduk di Indonesia dari tahun ke tahun terus mengalami peningkatan, hal ini akan berdampak pada peningkatan konsumsi produk peternakan (daging) yang secara tidak langsung memberikan peluang usaha dalam memajukan industri peternakan Indonesia termasuk perunggasan (Adli dan Sjofjan, 2020).

Untuk mengatasi itu salah satu langkah yang dilakukan ada memprediksi harga pakan jagung menggunakan salah satu model matematika yang disebut fuzzy time series. Logika fuzzy adalah suatu teknik yang digunakan untuk menyelesaikan suatu masalah dan juga bisa di implementasikan kedalam suatu perhitungan, dalam hal ini penulis mencoba melakukan prediksi harga jagung menggunakan logika fuzzy.

\section{MATERI DAN METODE}

Data yang didapatkan yaitu data historis atau rentan waktu dari berbagai literasi seperti hargaweb.id, jagungbisi.com, dan BPS dari tahun 2020-2021, kuarter pertama. Data tersebut nantinya akan dijadikan bahan perhitungan. Data dianalisa menggunakan $\mathrm{R}$ Studio. Kemudian algoritma fuzzy time series digunakan dalam penelitian sebagai berikut: 
Langkah-langkah tersebut dibagi menjadi 4 langkah yaitu: menentukan himpunan, membuat himpunan fuzzy, melakukan fuzzifikasi, membuat FLR, membuat FLRG dan mendefuzzifikasi menggunakan R Studio (Albright et al., 2011).

\section{Analisis Deret Waktu}

Fungsi utama analisis deret waktu sebenarnya adalah untuk meramalkan atau memprediksi data. Asumsi turunan pertama sebagai penjelajahan waktu. Dalam percobaan ini tidak ditentukan komponen secara acak melainkan data stasioner.Tujuan utama dalam menganalisis deret waktu adalah untuk memahami, menafsirkan, dan mengevaluasi perubahan fenomena dengan harapan dapat mengantisipasi jalannya peristiwa masa depan dengan lebih tepat (Devore and Berk, 2007).

\section{Fuzzy Set dan Forecasting}

Teori himpunan fuzzy dapat didefinisikan sebagai formalisasi matematika yang memungkinkan kita untuk menghilangkan ketidaktentuan dan menangani informasi yang tidak lengkap dan tidak akurat dari data kualitatif dan kuantitatif. Himpunan fuzzy adalah pengenalan metode matematika klasik (Rice, 2007)

\section{Seri Waktu Fuzzy (FTS)}

Fuzzy Time Series (FTS) merupakan metode peramalan data yang menggunakan konsep himpunan fuzzy sebagai dasar perhitungannya. Sistem peramalan dengan metode ini bekerja dengan cara mengembalikan pola dari data aktual kemudian digunakan untuk memproyeksikan data yang akan datang. Proses tersebut juga tidak memerlukan sistem pembelajaran dari sistem yang kompleks, seperti halnya dengan algoritma genetika dan jaringan saraf [5]. Selanjutnya Fuzzy Time Series (FTS) memiliki istilahistilah yang dipublikasikan yaitu Fuzzy Logic Relations (FLR) dan Fuzzy Logic Relations Group (FLRG). Fuzzy Logic Relations (FLR) merupakan logika fuzzy yang memiliki hubungan antara rangkaian asosiasi yang telah ditetapkan pada data sebelumnya dan lanjutan. Maka rentang hanya sama dengan rentang, namun hanya yang ditentukan adalah kelompok pembuatan dari rentang yang sama dengan kelompok tertimbang. Algoritma sebagai langkah berikut:

$\mathrm{U}=\{\mathrm{u} 1, \mathrm{u} 2 \ldots \mathrm{un}\}$ di mana himpunan fuzzy $\mathrm{Ai}(\mathrm{i}=1,2 \ldots \mathrm{n})$ didefinisikan sebagai berikut:

$$
\mathrm{Ai}=\mathrm{fAi}(\mathrm{uk}) / \mathrm{uk}+\mathrm{fAi}(\mathrm{uk}) / \mathrm{uk}+\ldots+\mathrm{f} \mathrm{Ai}(\mathrm{uk}) / \mathrm{uk} .
$$

Catatan: f Ai merupakan fungsi keanggotaan dari himpunan fuzzy Ai, uk merupakan unsur himpunan fuzzy $\mathrm{Ai}$, dan $\mathrm{f} \mathrm{Ai}(\mathrm{uk})$ adalah derajat keanggotaan uk milik $\mathrm{Ai}, \mathrm{k}=1,2, \ldots \mathrm{n}$.

\section{Langkah 1}

Menentukan wacana dan interval. Saat mendefinisikan alam semesta wacana, data minimum dan data maksimum dari data aktual yang diberikan masing-masing diperoleh sebagai Dmin dan Dmax. Berdasarkan Dmin dan Dmax, kita dapat mendefinisikan wacana universal sebagai: $\mathrm{U}=[\mathrm{Hm}-\mathrm{D} 1$, Dmaks + D2 $]$

Keterangan: D1 dan D2 adalah bilangan positif yang menentukan interval panjang efektif adalah model Fuzzy Time Series berbasis rata-rata.

\section{Langkah 2}

Dipisahkan antara interval. Partisi wacana universal $U$ menjadi beberapa interval yang sama. Biarkan wacana universal U dipartisi menjadi $n$ interval yang sama; perbedaan antara dua interval yang berurutan dapat didefinisikan sebagai $\ell$ sebagai berikut:

$\ell=[($ Dmaks $+\mathrm{D} 2)-($ Dmin $-\mathrm{D} 1)] / \mathrm{n}$

\section{Langkah 3}

Klasifikasikan set fuzzy. Tidak ada batasan dalam menentukan berapa banyak variabel linguistik yang dapat menjadi 
himpunan fuzzy. Jadi, "pendaftaran" dapat dijelaskan dengan himpunan fuzzy $\mathrm{A} 1=$ (tidak banyak), A2 = (tidak terlalu banyak), A3 = (banyak $),$ A4 = (banyak banyak $),$ A5 = (sangat banyak), A6 = (terlalu banyak). Untuk mempermudah, setiap himpunan fuzzy Ai $(i=1,2 \ldots 6)$ didefinisikan dalam 6 interval, yaitu :

$\mathrm{u} 1=[\mathrm{d} 1, \mathrm{~d} 2], \mathrm{u} 2=[\mathrm{d} 2, \mathrm{~d} 3], \mathrm{u} 3=[\mathrm{d} 3, \mathrm{~d} 4], \mathrm{u} 4=[\mathrm{d} 4, \mathrm{~d} 5], \mathrm{u} 5=[\mathrm{d} 5, \mathrm{~d} 6], \mathrm{u} 6=[\mathrm{d} 6, \mathrm{~d} 7] ;$

dengan demikian, himpunan fuzzy A1, A2...

A6 didefinisikan sebagai berikut:

$\mathrm{A} 1=\{1 / \mathrm{u} 1,0,5 / \mathrm{u} 2,0 / \mathrm{u} 3,0 / \mathrm{u} 4,0 / \mathrm{u} 5,0 / \mathrm{u} 6\}$,

$\mathrm{A} 2=\{0,5 / \mathrm{u} 1,1 / \mathrm{u} 2,0,5 / \mathrm{u} 3,0 / \mathrm{u} 4,0 / \mathrm{u} 5,0 / \mathrm{u} 6\}$,

$\mathrm{A} 3=\{0 / \mathrm{u} 1,0,5 / \mathrm{u} 2,1 / \mathrm{u} 3,0,5 / \mathrm{u} 4,0 / \mathrm{u} 5,0 / \mathrm{u} 6\}$,

$\mathrm{A} 4=\{0 / \mathrm{u} 1,0 / \mathrm{u} 2,0,5 / \mathrm{u} 3,1 / \mathrm{u} 4,0,5 / \mathrm{u} 5,0 / \mathrm{u} 6\}$,

$\mathrm{A} 5=\{0 / \mathrm{u} 1,0 / \mathrm{u} 2,0 / \mathrm{u} 3,0,5 / \mathrm{u} 4,1 / \mathrm{u} 5,0,5 / \mathrm{u} 6\}$,

A6 $=\{0 / \mathrm{u} 1,0 / \mathrm{u} 2,0 / \mathrm{u} 3,0 / \mathrm{u} 4,0,5 / \mathrm{u} 5,1 / \mathrm{u} 6\}$,

\section{Langkah 4}

Mengaburkan data. Mengaburkan data aktual. Langkah ini bertujuan untuk mencari himpunan fuzzy yang ekuivalen untuk setiap data masukan. Metode yang digunakan adalah dengan mendefinisikan satu set potongan untuk setiap Ai $(i=1 \ldots 6)$. Jika data deret waktu yang dikumpulkan termasuk dalam ui interval, maka itu adalah fuzzy ke himpunan fuzzy Ai.

\section{Langkah 5}

Buat hubungan fuzzy. grup hubungan logika fuzzy dapat dengan mudah diperoleh. Jika terdapat hubungan logika fuzzy yang diperoleh dari state A2, maka transisi dibuat ke state lain $\mathrm{Aj}, \mathrm{j}=1,2 \ldots, \mathrm{n}$, sebagai $\mathrm{A} 2 \rightarrow$ $\mathrm{A} 3, \mathrm{~A} 2 \rightarrow \mathrm{A} 2, \ldots, \mathrm{A} 2 \rightarrow \mathrm{A} 1 ;$ oleh karena itu, hubungan logika fuzzy dikelompokkan menjadi kelompok hubungan logika fuzzy [4] sebagai A2 $\rightarrow$ A1, A2, A3

\section{Langkah 6}

Defuzzy hasil peramalan. Hitung keluaran yang diperkirakan. Jika $\mathrm{F}(\mathrm{t}-1)=$ $\mathrm{Aj}$ maka peramalan $\mathrm{F}(\mathrm{t})$ dilakukan berdasarkan aturan sebagai berikut.

Aturan 1: Jika kelompok relasi logika fuzzy Aj kosong (yaitu, $\mathrm{Aj} \rightarrow \varnothing$ ), maka peramalan $F(t)$ adalah $\mathrm{mj}$, yang merupakan titik tengah dari interval uj: $F(t)=m j$.
Aturan 2: Jika grup hubungan logika fuzzy $\mathrm{Aj}$ adalah satu-ke-satu (yaitu, $\mathrm{Aj}$ $\rightarrow A k, j, k=1,2 \ldots, 6)$, maka peramalan $\mathrm{F}(\mathrm{t})$ adalah $\mathrm{mk}$, maka titik tengah interval uk: $F(t)=$ mk.

Aturan 3: Jika grup relasi logika fuzzy $\mathrm{Aj}$ adalah satu-ke-banyak (yaitu, $\mathrm{Aj}$ $\rightarrow \mathrm{A} 1, \mathrm{~A} 3, \mathrm{~A} 5, \mathrm{j}=1,2, \ldots, 6)$, maka peramalan $\mathrm{F}$

\section{HASIL DAN PEMBAHASAN}

Hasil dari interpretasi pada software R Studio menghasilak defuzzifikasi dengan acuan pada nilai FLR. Permisalan memprediksi harga jagung tahun Juli, 2020, maka prediksi pada tahun tersebut didapat dari hasil defuzzifikasi dengan persamaan pada tabel 1. Hasil dari prediksi selengkapnya ditampilkan pada tabel 1 dan 2.

Berdasarkan hasil penelitian fuzzy time series menghasilkan prediksi harga pada jagung menggunakan time series. Memprediksi harga akan cenderung berubah dari kisaran $\mathrm{Rp} /$ 4.000-4.400,- yang mana tingkat error hanya ada di level 8,23. Masih berada pada ambang yang stabil menurung Zang et al., (2012) tingkat error pada penelitian fuzzy berada di level $17 \%$ dimana hal ini masih bisa di toleransi mengingat ada berbagai model selain daripada markov chain ini. Hasil dari tabel 2. Menunjukan 
harga jagung akan cenderung naik mengingat jumlah kebutuhan yang juga meningkat.Harga jagung dipengaruhi oleh tingkat ketersedian, faktor nutrisim dan bibit. Sementara menurut Wang (2004) fuzzy time series adalah sebuha peramalan permintaan dalam industri dengan kapasitas terbatas telah menjadi topic yang mulai digunakan dalam berbagai sektor pertumbuhan diseluruh dunia.

Tabel 1. Prediksi harga dan set input untuk harga jagung

\begin{tabular}{cccccccc}
\hline Time & Year & Actual data & Fuzzy Data & Time & Year & Actual data & Fuzzy Data \\
\hline 1 & 2020 & 4.350 & A1 & 16 & 2020 & 4.350 & A2 \\
2 & 2020 & 4.350 & A1 & 17 & 2021 & 4.350 & A3 \\
5 & 2021 & 4.450 & A1 & 20 & 2021 & 4.450 & A4 \\
7 & 2021 & 4.450 & A2 & 30 & 2021 & 4.450 & A1 \\
\hline
\end{tabular}

Table 2. Prediksi harga jagung menggunakan set fuzzy series

\begin{tabular}{lcccc}
\hline Year & Actual data & Forecasted Value & Adjusted Value & Adjusted Forecasting value \\
\hline 2020 & 4200 & 4.149 & -3.86 & 6.44 \\
2020 & 4.350 & 4.156 & 0 & 6.55 \\
2021 & 4.322 & 4.123 & 0 & 0 \\
2021 & 4.344 & 4.322 & 0 & 0 \\
2021 & 4.350 & 4.411 & 8.23 & 0 \\
2021 & 4.421 & 4.333 & 8.11 & 0 \\
2021 & 4.450 & 4.333 & 7.67 & 4.83 \\
\hline
\end{tabular}

Studi ini menyajikan dua model yang dapat digunakan untuk memprediksi permintaan dalam berbagai bidang. Kedua model tersebut didasarkan pada kecerdasan buatan (AI) (Guney et al., 2018).

\section{KESIMPULAN}

Logika fuzzy atau time series mampu menyajikan prediksi harga jagung pada tahun 2020-2021 dengan keakuratan dengan tingkat error $8.23 \%$ artinya tidak berbeda jauh. Kedepannya banyak model matematika yang bisa digunakan untuk memprediksi dari harga bahan baku atau aspek lainnya pada industri peternakan.

\section{DAFTAR PUSTAKA}

Adli, D N, \& Sjofjan, O. (2020). Estimasi dan validasi kandungan energi bekatul sebagai pakan unggas dari komposisi kimia pakan. Jurnal Nutrisi Ternak Tropis.

Adli, Danung Nur, \& Sjofjan, O. (2020). Meta-analisis: pengaruh substitusi jagung dengan bahan pakal lokal terhadap kualitas karkas daging broiler. Jurnal Ilmu Peternakan Terapan, 3(2), 44-48. https://doi. org/10.25047/jipt.v3i2.1940

Adli, Danung Nur, Sjofjan, O., \& Mashudi, M. (2018). A study: nutrient content evaluation of dried poultry waste urea molasses block (dpw-umb) on proximate analysis. Jurnal Ilmu-Ilmu Peternakan, 28(1), 84-89. https://doi. org/10.21776/ub.jiip.2018.028.01.09

Adli, Danung Nur, Sjofjan, O., Natsir, M. H., \& Kusumaningtyaswati, A. (2020). Pengaruh kombinasi tepung kunyit (Curcuma domestica Val.) dan probiotik terhadap penampilan usus ayam pedaging. Jurnal Nutrisi Ternak Tropis Dan Ilmu Pakan, 2(1), 19-24. https://doi.org/10.24198/jnttip.v2i1.2 6587

Albright, S., Zappe, C., \& Winston, W. (2011). Data Analysis, Optimization, and Simulation Modeling. Cengage Learning. 
Devore, J., \& Berk, K. (2007). Modern Mathematical Statistics with Applications. Thomson Brooks/Cole.

Guney, H., Bakir, M. A., \& Aladag, C. H. (2018). A novel stochastic seasonal fuzzy time series forecasting model. International Journal of Fuzzy Systems, 20(3), 729-740. https://doi. org/10.1007/s40815-017-0385-z

Rice, J. (2007). Mathematical Statistics and Data Analysis. Thomson Brooks/Cole.

Sjofjan O., Adli D.N., Hanani P.K., \& Sulistiyaningrum D. (2020). The utilization of bay leaf (SyzygiumpolyanthumWalp) flour in feed on carcass quality, microflora instestine of broiler. International Journal of Engineering Technologies and Management Research, 6(11), 1-
9. https://doi.org/10.29121/ijetmr.v6.i 11.2019.458

Sjofjan, O., Nur Adli, D., Djunaidi, I., \& Kuncoro, K. (2020). Utilization of biogas liquid waste for starter in the fermentation of rice husk as a potential feed for poultry. ANIMAL PRODUCTION, 22(1), 24-30. https:// doi.org/10.20884/1.jap.2020.22.1.38

Wang, C.-H. (2004). Predicting tourism demand using fuzzy time series and hybrid grey theory. Tourism Management, 25(3), 367-374. https://doi.org/10.1016/S0261-5177 (03) 00132-8

Zeng, X., Shu, L., \& Jiang, J. (2016). Fuzzy time series forecasting based on grey model and markov chain. IAENG International Journal of Applied Mathematics, 46(4), 464-472. 